\title{
LA RED DE ENCUENTROS RESTAURATIVOS EN CASOS DE TERRORISMO. ECO SOCIAL DE UN PROYECTO INTERNACIONAL
}

\author{
Gema Varona Martínez \\ Investigadora doctora permanente, \\ Instituto Vasco de Criminología, Universidad del País Vasco \\ Title: The network on restorative encounters on terrorism. Social echo of an \\ international project
}

Resumen: Desde el significado de la justicia restaurativa en delitos de terrorismo, se contextualiza la red internacional de «encuentro de encuentros restaurativos» para efectuar un análisis temático del círculo de diálogo que tuvo lugar en San Sebastián, en 2019, cuando participantes de diversos países, que realizaron encuentros restaurativos en este ámbito, debatieron sus implicaciones personales, interpersonales y sociales. Finalmente se alude a los programas actuales de justicia restaurativa en el ámbito penitenciario.

Palabras clave: Justicia restaurativa; Terrorismo; Ámbito comparado; Impacto social; Prisión.

Abstract: This paper departs from the meaning of restorative justice in cases of terrorism. The international network called "encounter on restorative encounters" is contextualised and a thematic analysis is developed by considering the topics covered during the dialogue circle in San Sebastian in 2019, when participants of different countries - who took part in restorative encounters in cases of terrorism- debated personal, interpersonal and social implications. This will allow general reflections on current programs in prison.

Keywords: Restorative Justice; Terrorism; Comparative Framework; Social Impact; Prison. 
SUMARio: 1 . Introducción. - 2. El significado y los valores de la justicia restaurativa en relación con la victimización terrorista y otras victimizaciones graves. - 3. Contextualización de la red internacional «encuentro de encuentros» y dinámica de primer círculo de diálogo. -4 . Análisis temático del encuentro de encuentros. - 5. Discusión e implicaciones prácticas. - 6 . Bibliografía. - 7. Documentos. - 8. Prensa.

\section{Introducción}

«He tenido que entrar en prisión para encontrar justicia». Descontextualizada, esta frase ofrece muchas incógnitas. Por ello, debe precisarse que procede de un familiar de una víctima de homicidio que acudió a un encuentro restaurativo en Australia, muchos años después de la comisión del delito, cuando el victimario todavía se encontraba en un centro penitenciario ${ }^{1}$. La justicia de la que hablaba esta víctima no es la retributiva, sino que se trataba de una justicia más extraordinariamente compleja: una justicia basada en el diálogo para la reparación de daños con dimensiones recíprocas individuales y sociales. Sus palabras, recordadas ahora, son ilustrativas de cómo la entrada de las víctimas en el sistema penal y penitenciario no sólo no significa más punitivismo. Todo lo contrario, siempre y cuando se cambien inercias de la cultura jurídica y profesional (Igartua, 2015), se cumplan los estándares internacionales mínimos en la materia y se evalúen los programas restaurativos de forma crítica (Aertsen y Pali, 2017), una justicia penal no recelosa hacia las víctimas (Faraldo, 2014) puede ser una oportunidad para comenzar a reformular un sistema penal y penitenciario menos punitivo y más acorde con los derechos humanos (Bennet, 2007; Barr, 2013; Bargen et al., 2018; Bargen, Lyons y Harman, 2019). Ahora bien, el enfoque restaurativo sólo será posible, particularmente en delitos graves, si se abandona una visión esencialista, antagonista y patológica de la víctima (Herrera, 2014), es decir, una visión reduccionista que o la mitifica o la demoniza, en un entendimiento finalmente también reduccionista del significado de los derechos humanos de toda persona (Fattah, 2019).

Quizá la lectura de este primer párrafo frene al lector más pragmático por considerar la justicia restaurativa como algo utópico e idealizado. Sin embargo, debe advertirse que la justicia restaurativa, precisamente en contraste con la justicia clásica, cuenta ya con evaluaciones externas solventes en muchos países y con informes positivos de instituciones internacionales en materia de derechos humanos y justicia penal (Naciones Unidas, 2020; Sherman y Strang, 2009). Al hilo de ello, el objetivo de esta contribución es tanto descriptivo como analítico, si bien dentro de un

1 La frase pudo escucharse durante una visita organizada dentro del $15^{\circ}$ Simposio Internacional de Victimología en Perth (Australia), en julio de 2015. 
marco criminológico y victimológico y no jurídico penal (Ríos y Etxebarría, 2012) o procesal (Martínez Soto, 2016). Tras una introducción sobre el significado de la justicia restaurativa y el estado de la cuestión relativo a su uso en delitos de terrorismo, se contextualizará el proyecto de red internacional denominada como encuentro de encuentros restaurativos. Posteriormente, se efectuará un análisis temático del círculo de diálogo que tuvo lugar en Donostia/San Sebastián, en octubre de 2019, donde participantes de diversos países que realizaron encuentros restaurativos en este ámbito debatieron sus implicaciones personales, interpersonales y sociales. Finalmente, los resultados de ese análisis se pondrán en relación con el debate que se está produciendo en la actualidad, tanto en nuestro país como en otros europeos, sobre cuestiones prácticas respecto de la extensión general de los programas de justicia restaurativa en el ámbito penitenciario.

\section{El significado y los valores de la justicia restaurativa en relación con la victimización terrorista y otras victimizaciones graves}

En trabajos anteriores (Varona, 2014) se ha puesto de relieve cómo, desde su surgimiento a mediados de los años setenta del siglo pasado, la justicia restaurativa ha superado su momento mítico fundacional ${ }^{2}$ (Zehr, 2002) para expandirse a delitos graves, más allá de las fases de instrucción y enjuiciamiento (Martínez Escamilla y Sánchez Álvarez, 2011) y más allá de la jurisdicción de menores (Bernuz, 2014). Con mayor o menor impacto cuantitativo, por número de casos derivados, y con mayor o menor cobertura legal, dicha expansión es ya un hecho en muchos países de todos los continentes (Weitekamp y Kerner, 2012; United Nations, 2020).

Sin perjuicio de las diferentes miradas teóricas que han influido en el surgimiento y desarrollo de la justicia restaurativa, de carácter religioso o espiritual (Zehr, 2002; Bianchi, 1994); político (Mathiesen, 1974; Davis, 2005); o jurídico-criminológico (Christie, 1977, 2009; Steinert, 1988; Hulsman, 1991; Braithwaite, 1989; Pepinsky, 1998), existe ya un conjunto normativo de estándares mínimos en justicia restaurativa. En concreto y aunque con carácter de soft law o derecho no jurídicamente vinculante

2 En 1974, dos adolescentes que habían consumido drogas cometieron delitos de daños en numerosas propiedades en la población de Elmira (Ontario). Dentro de una perspectiva de justicia comunitaria que podría recordar en cierta forma a prácticas indígenas (Blagg y Anthony, 2019), dos jóvenes oficiales de probation decidieron proponer al juez la posibilidad de un encuentro cara a cara de los jóvenes con sus víctimas, para pedir disculpas y acordar una reparación, que evitaría su paso por un centro de internamiento. Surgió así el Programa de Reconciliación Víctima Ofensor (VORP, por sus siglas en inglés). 
aunque sí éticamente, en el ámbito universal deben mencionarse cuatro Resoluciones en el ámbito de las Naciones Unidas: la Resolución del Consejo Económico y Social 1999/26, de 28 de julio de 1999, titulada «Elaboración y aplicación de medidas de mediación y justicia retributiva en materia de justicia penal», en la que se solicitó a la Comisión de Prevención del Delito y Justicia Penal que considerara la conveniencia de formular normas en materia de mediación y justicia restaurativa; las Resoluciones 2000/14, de 27 de julio de 2000, y 2002/12, de 24 de julio de 2002, tituladas respectivamente «Principios básicos sobre la utilización de programas de justicia restaurativa en materia penal» $\mathrm{y}$ «Principios básicos para la aplicación de programas de justicia restaurativa en materia penal»; y la Resolución 2016/17, del 26 de julio de 2016 sobre «Justicia restaurativa en asuntos penales». Auspiciado por las Naciones Unidas, Dandurand y Griffiths (2006) publicaron un influente manual sobre la puesta en marcha de programas restaurativos para su aplicación universal. Sin perjuicio de la existencia de manuales internos en cada país (Brookes, 2002), el Foro Europeo de Justicia Restaurativa (2018) también publicó unas pautas para asegurar el cumplimiento de los estándares internacionales, tanto universales como regionales europeos ${ }^{3}$.

En la segunda edición del manual de las Naciones Unidas (United Nations, 2020, p. 1) se define la justicia restaurativa como «una respuesta flexible, participativa y de resolución de problemas que puede

3 En el ámbito del derecho no vinculante, en el contexto del Consejo de Europa, la Recomendación CM/Rec(2018)8 del Comité de Ministros a los Estados miembros en materia de justicia restaurativa penal define la justicia restaurativa como cualquier proceso que permita, a aquellas personas dañadas por el delito y a las personas responsables del daño, previo consentimiento libre, participar activamente en la resolución de las consecuencias resultantes, con la ayuda de un tercero independiente y cualificado (denominado «facilitador»). Según esta norma, la justicia restaurativa consiste en un diálogo (ya sea directo o indirecto) entre la víctima y el ofensor, y también puede implicar, si procede, a otras personas afectadas por un delito directa o indirectamente. Entre ellas, pueden estar personas de apoyo a las víctimas y ofensores, profesionales y miembros o representantes de las comunidades concernidas. Según el Anexo II de la Recomendación CM/Rec (2010)1 del Comité de Ministros del Consejo de Europa sobre las reglas relativas a la probation, referida a la ejecución de penas y medidas en medio abierto, adoptada el 20 de enero de 2010, la justicia restaurativa incluye enfoques y programas basados en varios postulados: a) una respuesta apropiada al delito debe permitir reparar, en la media posible, el daño sufrido por la víctima; b) es necesario llevar a los infractores a entender que su comportamiento no es aceptable y que tiene consecuencias reales para la víctima y la comunidad; c) los infractores pueden y deben asumir la responsabilidad de sus actos; d) las víctimas deben tener la oportunidad de expresar sus necesidades y participar en reflexiones que lleven a determinar la mejor manera en que el infractor repare el perjuicio causado; y e) la comunidad tiene la responsabilidad de contribuir a este proceso. Por su parte, dentro de la Unión Europea y con carácter de derecho vinculante, en el artículo 2. 1. d) de la Directiva 2012/29/UE, se habla de «cualquier proceso» y en su considerando 46 existe una mención expresa a la mediación, conferencias y círculos. En la transposición de esta Directiva al marco español, el artículo 15 de la Ley 4/2015, de 27 de abril, del Estatuto de la víctima del delito, se refiere a los «servicios de justicia restaurativa». 
proporcionar un camino de justicia complementario o alternativo. Puede mejorar el acceso a la justicia, particularmente para las víctimas del delito y poblaciones vulnerables y marginalizadas, inclusive en contextos transicionales». De forma novedosa, el capítulo sexto de este manual se destina a los programas enfocados en los delitos graves, donde se pide que haya una valoración y prevención del riesgo en cada caso específico y que se realice la intervención por personas formadas en las necesidades de las víctimas y, en concreto, en el potencial impacto del trauma en sus vidas, de forma que pueda evitarse la victimización secundaria y la revictimización (Caruth, 1995; McGarry y Walklate, 2015; Pycroft y Christensen-Schneider, 2021; Jorge, 2021).

En el caso de los delitos graves, la justicia restaurativa conllevará normalmente su vinculación con el sistema penitenciario. Considerando las investigaciones previas realizadas a lo largo de las últimas décadas (Varona, 2021), la justicia restaurativa desarrollada en el ámbito penitenciario se entiende complementaria de la justicia clásica y uno de los debates suscitados en torno a ella se refiere a su carácter transformador dentro del propio medio penitenciario (Pali y Pelikan, 2014; Feest, 2015; Ollero, 2018). Ese carácter transformador no se circunscribe sólo al efecto potencial en la reducción del tiempo en prisión o a la repercusión jurídico-penal de la justicia restaurativa en general, sino principalmente al cuestionamiento de las condiciones socioestructurales que permiten y ahondan injusticias sociales. En relación con ello, pero en sentido contrario, aplicada tanto fuera como dentro de prisión, también se discute la conceptualización de la justicia restaurativa como terapia para la recuperación del bienestar psicológico de la víctima o la reinserción del ofensor, términos problemáticos desde una perspectiva crítica (Carlen, 2015). Sin perjuicio de sus posibles efectos terapéuticos para ambos y de las limitaciones de sus dinámicas, siempre voluntarias y confidenciales, la justicia restaurativa debe entenderse como servicio público más adecuado a las necesidades y responsabilidades suscitadas, en un diálogo en que se convoca a las personas concernidas (no sólo víctima y victimario) frente al daño producido que nunca podrá quedar acotado en una definición y una respuesta estrictamente legal (Hagemann, 2003; 2012; Johnstone, 2019; Varona, 20204). La justicia restaurativa, que, como hemos visto, obedece a otros principios distintos de los estrictamente jurídicopenales clásicos, aúna en un espacio y tiempo, buscado y preparado, la prevención y la reparación de la victimización en sentido amplio. Su objetivo es romper la expansión de los círculos de daños (también aquellos creados por el propio sistema penal) y crear algo inesperado, en particular para delitos graves. Lo inesperado es posible al permitir cuestionar

${ }^{4}$ Como se ha indicado en otros trabajos, la crítica centrada en la terapeutización de la justicia, cuando se enfoca respecto de la justicia restaurativa, se centra no tanto en la idea de los derechos frente al concepto de necesidades, sino del carácter transformador de sus prácticas y programas (Waklate, 2019; Johnstone, 2019; Varona, 2019). 
la separación radical entre razón y emoción, como lo hacen también diversos estudios neurocientíficos (Reisyan, 2016), así como dar entrada a una verdad dialógica más allá de la jurídica y considerar el impacto real del sistema penal y penitenciario en las personas más afectadas por el mismo para contraponerlo con sus principios teóricos en un Estado social y democrático de Derecho.

Estas cuestiones críticas sobre la justicia restaurativa en prisión para cualquier delito, y en general sobre los valores propios que la diferencian de la justicia clásica, pueden enfocarse de forma pormenorizada respecto de la victimización terrorista ${ }^{5}$. Recordando las definiciones de justicia restaurativa indicadas anteriormente, podemos preguntarnos hasta qué punto puede ser aplicable a los delitos de terrorismo, en su caso en el ámbito penitenciario (Varona, 2012). Según la Resolución 73/211 sobre medidas para eliminar el terrorismo internacional, aprobada por la Asamblea General el 20 de diciembre de 2018, los actos terroristas pueden identificarse como «actos criminales con fines políticos realizados o calculados con la intención de provocar un estado de terror en la población en general, en uno de sus grupos o en determinadas personas» que resultan «injustificables en toda circunstancia, cualesquiera que sean las consideraciones políticas, filosóficas, ideológicas, raciales, étnicas, religiosas o de otra índole que se aleguen para justificarlos». Por su parte, la Oficina de las Naciones Unidas sobre Drogas y Delincuencia (s.f.), en la sección de su página web sobre prevención del terrorismo, propuso la siguiente definición: «El terrorismo es un método de acción violenta reiterada que infunde ansiedad, empleado por actores individuales, grupales o estatales (semi) clandestinos, por razones idiosincrásicas, criminales o políticas, donde - en contraste con el asesinato- los objetivos directos de la violencia no son los principales objetivos. Las víctimas humanas de la violencia se eligen generalmente al azar (objetivos de oportunidad) o selectivamente dentro de una población diana (objetivos representativos o simbólicos), y sirven como generadores de mensaje. Los procesos de comunicación basados en la amenaza y en la violencia entre el terrorista (su organización), las víctimas (puestas en peligro) y los objetivos principales se utilizan para manipular al objetivo principal (la/s audiencia/s), convirtiéndolo en un objeto de terror, de demandas o de atención, dependiendo si se busca principalmente la intimidación, la coerción o la propaganda».

Sin perjuicio del debate político y jurídico sobre la definición del terrorismo, desde un punto de vista victimológico (Varona, 2018; Fourez, 2021) ${ }^{6}$, la victimización terrorista se enmarca dentro de los delitos

5 Sin perjuicio de poder considerar también la potencialidad de la justicia restaurativa para delitos prescritos no enjuiciados, tanto en victimización terrorista como en otras de carácter grave.

6 Según la Directiva (UE) 2017/541 del Parlamento Europeo y del Consejo, de 15 de marzo de 2017 relativa a la lucha contra el terrorismo, en relación con su art. 3. 2, se en- 
graves, pero supone en todo caso no sólo un daño individual (definido por la cosificación e instrumentalización de las víctimas) y social (definido por la extensión de la victimización indirecta), sino también político (definido por la amenaza al pluralismo democrático). Además, dependiendo de diferentes modalidades, contextos y perfiles de victimización, como puede ser un atentado en masa, supone una victimización con unas características particularmente lesivas para las víctimas (Beristain, 2007; Echeburúa, 2007; VV. AA. 2008; Letschert, Staiger y Pemberton 2010; Albrecht y Kilchling, 2010; García-Vera y Sanz 2016; EU Centre of Expertise for Victims of Terrorism, 2020).

Por tanto, en el terrorismo se entrecruzan aspectos de macrovictimización que no se encuentran en otros delitos a los que se suele aplicar la justicia restaurativa, sin perjuicio de orientaciones restaurativas en marcos transicionales (Eriksson, 2009; Gil y Maculan, 2017). No obstante, desde diversas organizaciones internacionales (Biffi, 2020), se ha puesto de relieve la pertinencia de la justicia restaurativa para los delitos de terrorismo y la violencia política, precisamente como un mecanismo de humanización y descosificación de las víctimas, de generación de empatía y de coherencia con los principios de diálogo democrático; todo ello sin obviar los posibles riesgos de impunidad, banalización y justificación de la violencia, y la potencial instrumentalización de las víctimas en relación con el fin de la resocialización del victimario (Pemberton, Winkel y Groenhuijsen, 2007; Pemberton, 2014).

Como señala Biffi (2020), el daño de la victimización terrorista se justifica por seguir una determinada ideología y estrategia política como respuesta a una actitud precisamente victimista de los propios victimarios que contemplan a las víctimas como víctimas merecidas o colaterales de un conflicto que supera las vidas o intereses individuales. En ocasiones, las personas que se unen a un grupo terrorista encuentran en él respuesta a su búsqueda de pertenencia y sentido vital. Suele suceder que unas políticas antiterroristas abusivas conlleven que se refuerce ese victimismo y que se cumpla el llamado cálculo terrorista según el cual esas extralimitaciones estatales legitiman la visión de los perpetradores de guerra justa o de legítima defensa. No obstante, puede criticarse el lenguaje de ciertas organizaciones de justicia restaurativa (Biffi, 2020), cuando hablan de fomentar el diálogo entre «ambas partes» (víctimas, perpetradores) ya que la justicia

tiende por víctima del terrorismo la definida en el artículo 2 de la Directiva 2012/29/UE, es decir, toda persona física que haya sufrido un daño o perjuicio, en particular lesiones físicas o mentales, daños emocionales o un perjuicio económico, directamente causados por un delito de terrorismo, o el familiar de una persona cuya muerte haya sido directamente causada por un delito de terrorismo y que haya sufrido un daño o perjuicio como consecuencia de la muerte de dicha persona. Los familiares de las víctimas supervivientes del terrorismo, según se definen en el citado artículo, tienen acceso a servicios de apoyo a las víctimas y medidas de protección de conformidad con lo dispuesto en dicha Directiva (vid. considerando 27). Cfr. EU Centre of Expertise for Victims of Terrorism (2020). 
restaurativa no es mediación penal entre partes, sino que surge de una visión coherente de los derechos humanos donde no se puede invocar una posible vulneración de los mismos para vulnerar otros, en un ciclo perpetuo de violencia o del victimismo «y yo más» (Varona, 2020).

Es preciso evitar el partidismo y la manipulación política de la justicia restaurativa en este campo, pero si el terrorismo produce un daño político, al eliminar el pluralismo democrático ${ }^{7}$, el encuentro restaurativo también deberá abordar mínimamente ese daño político, encarnado en las víctimas supervivientes o indirectas. Por ello, la cuestión fundamental del uso de la justicia restaurativa en delitos de terrorismo es preguntarse por la formación y el papel de la persona facilitadora respecto de la deslegitimación de la violencia con fines políticos. No se trata de crear jerarquías de sufrimientos, sino de abordar la injusticia concreta que convoca para entender, pero no para justificar (Mate, 2011). Al poner el foco en las vidas concretas, en su caso eliminadas porque el fin justificaba los medios en un monólogo de violencia, la víctima puede recordar a la persona que cometió el daño las palabras de Stefan Zweig (2012), en boca de Castellio, cuando dice que matar a una persona es simplemente matar a una persona, no defender una idea (en su caso, de denuncia de otra violación de derechos distinta). La persona facilitadora del encuentro debe promover la posibilidad de diálogo, crítico y complejo, para reparar y prevenir tanto en clave interpersonal como social. En este sentido, dados la voluntariedad y el compromiso, la clave transformadora de la justicia restaurativa se encuentra en romper con las respuestas que imponen la separación del intercambio de ideas entre víctimas, victimarios y sociedad, pero siempre bajo el presupuesto del «nunca más contra nadie más», lo que puede implicar una mirada preventiva pedagógica, basada en mínimos éticos, que no tiene por qué ver con moralismos, sino con caminos optativos más difíciles de andar porque requieren voluntariedad, flexibilidad de formatos y respeto de los tiempos de las personas implicadas (Chapman, 2018; Biffi y Chapman, 2019).

\section{Contextualización de la red internacional «encuentro de encuentros» y dinámica de primer círculo de diálogo}

Habiendo trabajado este tema anteriormente (Varona, 1997; 2012), y en relación con los encuentros realizados en el País Vasco (Pascual, 2013; Olalde, 2014) ${ }^{8}$, las cuestiones anteriores habían sido objeto de investigaciones

7 Véase al respecto la Exposición de Motivos de la Ley vasca 4/2008, de 19 de junio, de Reconocimiento y Reparación a las Víctimas del Terrorismo y el Preámbulo de la Ley estatal 29/2011, de 22 de septiembre, de Reconocimiento y Protección Integral a las Víctimas del Terrorismo.

${ }_{8}$ Asimismo, con alusiones expresas a la justicia restaurativa, vid. el Programa para el desarrollo de la política penitenciaria de reinserción individual en el marco de la ley, 
específicas por parte del Laboratorio de Teoría y Práctica de Justicia Restaurativa del Instituto Vasco de Criminología (IVAC/KREI) de la Universidad del País Vasco ${ }^{9}$, así como de seminarios específicos del Foro Europeo de Justicia Restaurativa (FEJR). Dentro de dicha línea de investigación-acción (Vanfraechem y Aertsen, 2017), los días 17 y 18 de octubre de 2019, se realizó un círculo de diálogo ${ }^{10}$ en el IVAC/KREI, en el campus de Gipuzkoa del

publicado en la web de Instituciones Penitenciarias, el 30 de abril de 2012. Cfr. el llamado Programa Hitzeman, la "vía legal». Programa de apoyo a los procesos legales de resocialización de personas presas, publicado en 2014 por la Secretaría de Paz y Convivencia del Gobierno Vasco.

9 En una encuesta realizada por el IVAC/KREI, a finales del año 2013, con entrevistas personales a más de 150 familiares de víctimas asesinadas por grupos terroristas, fundamentalmente de ETA, residentes en el País Vasco, se constató el interés de los mismos en la justicia restaurativa (Varona, de la Cuesta y Echeburúa, 2016). Cfr. Varona y Soleto (2014).

10 Siguiendo la propuesta de García Peñafiel y Cartuyvels (2018), los pasos de un círculo de diálogo entre profesionales o expertos, siempre en una disposición de sillas en círculo, son los siguientes: 1. Reunir a unos 15/20 participantes, varias horas con pausas, asegurando la diversidad y equilibrio, para conversar de forma ordenada sobre una problemática que les concierne, más allá de su labor profesional, para entender conflictos de poder y dificultades de comunicación en la práctica. 2 . Al inicio, la persona facilitadora - o cofacilitadora-, debe procurar que las personas se sienten en círculo de forma que se mezclen sin que puedan identificarse "partes» $\mathrm{u}$ «opuestos». Pueden proporcionarse adhesivos u hojas para poner el nombre de cada persona, delante de la silla, en el suelo. 3. El círculo se configura como un modo narrativo grupal de construcción de conocimiento híbrido, diferente de los grupos de discusión al uso. En los círculos de diálogo restaurativo la aportación de información y su análisis se hace por los participantes en el grupo, con ayuda de los facilitadores, quienes lo dinamizan y controlan que se respeten los principios éticos básicos de toda conversación, favoreciendo que todas las personas puedan participar y ser escuchadas (se puede utilizar un objeto, quizá representativo del tema en cuestión y que sea fácil de pasar, para que sólo la persona que lo tenga en sus manos puede hablar en ese momento). Dentro de dichos principios se incluye la imparcialidad y confidencialidad, sin perjuicio de poder recoger algunos puntos generales a modo de conclusiones donde se puedan identificar puntos o redefinirlos para seguir trabajando en ellos en el futuro. 4. Las personas facilitadoras pueden aportar algunos puntos para la reflexión, quizá a modo de preguntas, para que las personas participantes puedan pensar sobre ellos antes de acudir al círculo, pero en modo alguno se trata de que "suelten algo preparado", sino que se busca la escucha de los demás y la interacción con lo que los demás expresen para poder cuestionar o matizar asunciones propias y ensanchar perspectivas. Se favorece una ética de la comunicación, por encima del saber académico tradicional, para proporcionar un espacio seguro para narrar y escuchar desde donde pueden darse cambios relacionales. Las personas participantes son todas consideradas con igual amabilidad y trascendencia, como sujetos reflexivos y no como objetos para extraer información, donde unos tienen más autoridad que otros. 5. Se recomienda partir de historias, experiencias propias o percepciones concretas por parte de cada participante y permitir que los demás puedan hacer preguntas y reinterpretarlas. Se trabaja sobre realidades vividas por sus narradores más que sobre abstracciones. Ello permite asegurar el interés personal por la problemática, visibilizar la complejidad y su impacto y salir del rol asignado, entrando en lo humano, sin exponer a nadie a situaciones o emociones que no desee mostrar o le resulten incómodas en grupo. Las personas facilitadoras supervisan posiciones de dominio. Las personas facilitadoras deben ser capaces de observar y escuchar sin enjuiciar, mostrando empatía, desde la imparcialidad sin mostrar preferencias. Al terminar, las personas facilitadoras pueden ayudar a reformular algunos temas o puntos para poder mover las posiciones 
País Vasco, con diferentes agentes participantes en encuentros restaurativos en casos de terrorismo en diversos países, con el objetivo de contrastar la potencialidad de la justicia restaurativa en este campo. La iniciativa surgió durante un curso de verano en Barcelona ${ }^{11}$, organizado por el FEJR, la Confederación Europea de Probation (CEP) y la Organización Europea de Servicios de Prisión (EUROPRIS). Un año antes también se había invitado a diversos expertos internacionales, entre ellos Tim Chapman ${ }^{12}$ a un círculo de diálogo en el IVAC/KREI para debatir, con diversas víctimas del País Vasco, sobre la noción de memoria restaurativa (Varona, 2020).

En la preparación de los contenidos y la metodología del círculo de diálogo, se decidió invitar a personas del País Vasco (España) ${ }^{13}$, Italia ${ }^{14}$, Alemania $^{15}$, Bélgica ${ }^{16}$, Israel y Palestina ${ }^{17}$ (Varona, 2020). De las 26 personas invitadas que confirmaron la aceptación para participar, pudieron

iniciales, en su caso, o permitir cuestionarlas y re-enmarcarlas, desbloqueando posibles visiones antagonistas sin perjuicio de considerar que la problemática requiere un trabajo a mayor escala y largo plazo, al existir necesidades más profundas o asimetrías de poder de carácter cultural y estructural.

11 Titulado Reimagining Violent Extremism (restoratively). Radicalisation \& Violent Extremist Offenders CJPE Summer Course, celebrado en Barcelona, del 3 al 6 de Julio de 2018. Vid. Biffi (2018). En dicho curso coincidió un experto del IVAC/KREI con Claudia Mazzucato y Guido Bertagna, ambos facilitadores y, respectivamente, profesora de Derecho penal de la Universidad del Sagrado Corazón de Milán y sacerdote jesuita con amplia experiencia en el apoyo de menores y adultos en sus procesos de reinserción. Ambos contaban con más de diez años de experiencia como facilitadores de un grupo de encuentro de víctimas y exterroristas de las Brigadas Rojas que actuaron en las décadas de los setenta y ochenta en Italia. Desde la autofinanciación de la iniciativa con diversas modalidades de encuentros restaurativos (mediación y círculos), en 2007 se realizó un primer encuentro con 9 personas, en 2014 se reunieron más de 60 personas y ya se han realizado más de cien encuentros que involucran a diferentes miembros de la comunidad, además de a víctimas y ex ofensores.

12 Tim Chapman, investigador independiente y formador norirlandés en justicia restaurativa, quien también dirige la Junta del FEJR.

${ }_{13}$ Participantes en encuentros restaurativos vinculados a la denominada vía Nanclares de ex miembros de ETA (Pascual, 2013) —si bien también existen experiencias con condenados por terrorismo yihadista-y otros proyectos restaurativos (Dürkhop, 2020), también con víctimas del grupo terrorista GAL (Lasa en García Arrizabalaga, 2019; Olalde, 2020). Para Maixabel Lasa la justicia restaurativa es «encontrarse con una persona que te ha hecho mucho daño pero que, a la vez, es capaz de decirte después de años: «Estaba equivocado. Lo que hice no tuvo que suceder nunca». Eso moralmente para mí es mucho más satisfactorio que el valor económico o la condena en sí misma» (Muñoz, 2019, p. 37). Otras víctimas que participaron en este encuentro de encuentros, no están tan interesadas en este aspecto interpersonal de la justicia restaurativa al cual, en todo caso, Maixabel Lasa otorga también una dimensión social. Vid. Sistiaga y CortésCavanillas (2019).

14 Vid. Bertagna, Ceretti y Mazzucato (2015). Cfr. Soulou (2017; 2018).

15 Si bien, finalmente, nadie pudo acudir de Alemania al encuentro en Donostia/San Sebastián, véase el testimonio de una víctima indirecta, la hermana de una víctima del Ejército Rojo, Edward Pimental en https://kathleenpequeno.com/edward-pimental-andthe-raf/, donde se presta al contacto con antiguos integrantes de la banda armada, según indica, en un compromiso de búsqueda de la paz. Véase, sobre su experiencia, la película titulada The Worst Things (2017) (http://worstthingfilm.com/). Cfr. Pali (2018; 2021). 
hacerlo finalmente 23. De cada país acudieron uno o dos facilitadores de los encuentros, una o varias víctimas, una o varias personas condenadas ${ }^{18}$ y uno o varios estudiantes jóvenes o investigadores, en representación de la comunidad más cercana (Chapman, 2012; Wood y Suzuki, 2020 ${ }^{19}$. Al tratarse de un círculo de diálogo, con una metodología coherente con la justicia restaurativa, se propició la diversidad de miradas, narraciones, emociones y hechos. De forma secuencial, siguiéndose la dinámica de los círculos restaurativos, se utilizó un objeto de palabra y otro de cese de palabra para facilitar la comunicación entre tantas personas. Clair Aldington (2020), una investigadora escocesa experta en aplicar arte colaborativo en círculos restaurativos, planteó una actividad creativa que permitió expresarse más allá del intercambio de impresiones alrededor de las preguntas planteadas.

El idioma de trabajo fue el inglés, proporcionando traducción informal por parte de los integrantes del encuentro, en modo «susurro». Todos los participantes agradecieron finalmente la escucha en el idioma propio de los intervinientes ya que permitía transmitir su ritmo y tono ante experiencias tan profundas ${ }^{20}$. Antes del encuentro se solicitó por una de las personas condenadas la traducción al inglés de un texto que contenía su reflexión sobre la necesidad de pedir perdón, para ser distribuida a los participantes. Su lectura suscitó un debate posterior.

El círculo se inició recalcando la necesidad de ser conscientes de las diferencias entre países en cuanto a la contextualización de la victimización terrorista y del uso de la justicia restaurativa, contextualización que, por motivos de tiempo, no se pudo realizar en profundidad y se remitió a la bibliografía especializada. Se aclaró que este encuentro de encuentros suponía un espacio de respeto y de confidencialidad

16 Acudió la facilitadora y experta en justicia restaurativa, Katrien Lauwaert (2015), pionera también, junto con el Profesor Ivo Aertsen, en la investigación y establecimiento de estándares internacionales sobre justicia restaurativa en delitos de terrorismo.

17 De Israel y Palestina vinieron personas que trabajan en la organización «Círculo de padres». Véase su página web en https://theparentscircle.org/en/pcff-home-page-en/. Con el simbolismo de la música, véase la intervención de una de las participantes en nuestro encuentro, Robi Damelin, en una canción dedicada a dicho círculo en https://youtu. be/9205P-o1Azc. Véase también el tráiler de la película One day after peace, en https:// www.youtube.com/watch?v=W1kSkdOBFQo. Vid. Aertsen et al. (2018).

${ }_{18}$ La mayoría ya habían cumplido sus penas por lo que este círculo de diálogo no tenía vinculación con el sistema penitenciario de ningún país. En algún caso excepcional, la persona ostentaba el doble rol de víctima y victimario.

19 También acudió Roberto Moreno, entonces técnico del Gobierno Vasco responsable de los servicios públicos de justicia restaurativa y hoy responsable del área de justicia del Ararteko/Defensoría del Pueblo Vasco.

20 En ese encuentro de encuentros, previa información y aceptación por las personas afectadas, se encontraron por primera vez una víctima y la persona que ordenó el asesinato de su marido. 
(algunos participantes pidieron que no se identificaran sus nombres, fundamentalmente fueron personas responsables de la victimización, alguna indicó que sus familiares no veían con buenos ojos esa participación, si bien algunas víctimas también comentaron que no habían hablado de este encuentro con sus hijos). Los facilitadores de los distintos países y otras personas de apoyo en esta labor, aseguraron una atmósfera de confianza en que cada persona pudiera sentirse bien, física y emocionalmente, con legitimidad para contar la propia experiencia, como algo único y valioso.

Todos los participantes en este círculo de diálogo, que en la actualidad sigue abierto ${ }^{21}$, indicaron su interés en poder continuar con reuniones anuales del grupo, invitando a más personas. De hecho, algunas de las personas participantes coincidieron unas semanas después de la realización del encuentro, en diciembre de 2019, en una actividad de la Red de Concienciación sobre la Radicalización (Radicalisation Awareness Network, RAN), en línea con los objetivos de memorialización pedagógica y preventiva del propio encuentro de encuentros.

\section{Análisis temático del encuentro de encuentros}

De forma breve, utilizando una metodología cualitativa, dentro del marco de la teoría fundamentada constructivista, se han podido analizar los temas emergentes en el encuentro de encuentros realizado en noviembre de 2019, mediante un análisis temático híbrido (Swain, 2018) con identificación de temas a priori y posteriori. Los temas a priori de análisis, extraídos de una revisión básica de la bibliografía, fueron aquellos que estructuraron el encuentro de encuentros, en concreto: la contextualización del daño producido; la motivación para participar de los integrantes del círculo en programas restaurativos en sus países; las dificultades encontradas y sus formas de abordaje; y el impacto personal y el impacto social de la justicia restaurativa. Los temas a posteriori o

${ }^{21}$ En 2020 se planificó un encuentro en la Universidad del Sagrado Corazón de Milán, pero tuvo que posponerse por la pandemia, si bien ese año se publicaron algunas reflexiones sobre dicho encuentro de encuentros (Varona, 2020) y se presentaron vídeos sobre el mismo en diversos congresos internacionales que dieron lugar a debates con sus participantes. En el marco de la RJ World 2020 - eConference, vid. en https://vimeo. com/444917420/8905573b65; en el marco del REstART Festival, vid. https://ehutb.ehu.es/ video/6042196df82b2b3a308b4b71. En 2021 se ha planificado una exposición itinerante sobre la reflexión artística de la dinámica de arte colaborativo por parte de C. Aldington, propiciando también el debate online con estudiantes (en el caso español, el 16 de noviembre de 2021, con motivo del Encuentro en homenaje a Antonio Beristain). En 2022, se realizará otro círculo de diálogo con los participantes del primero, y otros nuevos invitados, durante el Simposio Mundial de Victimología, donde también se prevé un plenario con el diálogo entre dos víctimas vascas participantes en proyectos de justicia restaurativa en casos de terrorismo. 
emergentes, dentro de las propias prioridades de los participantes, resultaron de la búsqueda de patrones de significados comunes y divergentes, según veremos en algún extracto mencionado en el siguiente apartado. Los temas a posteriori proceden de un proceso de reflexión inductivo que parte de las experiencias de las personas participantes para poder sistematizarlas y compararlas, sin distinguir entre códigos o temas, ya que ambos conceptos se entienden como unidades de significado, más o menos extensas. Dada la necesidad de confidencialidad y el carácter piloto e informal del círculo de diálogo, se recogieron notas a mano, además de los materiales de arte colaborativo producidos durante las actividades. No se utilizó un software para el análisis cualitativo de los datos, atendiendo a la flexibilidad y especificidad del contenido (Basit, 2003). Por tanto, la sistematización de las notas se realizó manualmente y mediante un procesador de textos, considerando el contexto excepcional del encuentro, de gran carga emotiva. Las conclusiones fueron contrastadas con las personas participantes para favorecer su integridad. En todo caso, ya que nos encontramos dentro de una metodología cualitativa y los participantes fueron seleccionados mediante una técnica de bola de nieve, dada la sensibilidad del tema, no se pretendió la generalización, sino la extracción de conclusiones provisionales que permitieran estudios más profundos y prácticas de justicia restaurativa más adecuadas en este campo.

A continuación, haremos referencia brevemente a los seis temas emergentes del encuentro de encuentros que pudieron desgranarse del círculo de diálogo: similitudes y diferencias; rectificación, reconocimiento y reconexión; rituales y energía emocional; el significado del perdón; impacto personal y eco social; y el valor del arte colaborativo.

\subsection{Similitudes y diferencias de las iniciativas en los diferentes países}

En todos los casos, los encuentros se produjeron, y se siguen produciendo, bastantes años después de la victimización terrorista -incluyendo el cese o disolución del grupo- ${ }^{22}$. La modalidad de victimización se refiere, en su mayoría, a asesinatos, por lo que son las víctimas indirectas las que participan en los encuentros restaurativos, con una mayor presencia de mujeres (viudas, hijas, hermanas...). Hay una búsqueda de

22 En el caso de Bélgica existe un interés particular respecto del terrorismo yihadista. Cfr., en otros países, Ruiz Yamuza y Ravagnani (2018) y, de forma general, Baldoli (2020). En el manual de las Naciones Unidas respecto de internos que han caído en la radicalización violenta y para la prevención del extremismo violento en las prisiones, se realiza una mención expresa a la justicia restaurativa, en particular dentro de programas de reentrada en la comunidad (United Nations, 2016, p. 126; Gavrielides, 2018). 
solidaridad para con las víctimas, como agentes con intereses prosociales que ofrecen su capacidad de convivencia, a pesar del trauma sufrido. Algunas víctimas están más interesadas en la reparación de la victimización secundaria producida por las instituciones y por la sociedad y, en todo caso, en la educación de las futuras generaciones. Las personas responsables de la victimización que acuden al círculo son todas hombres ${ }^{23}$. Su interés en los programas restaurativos y en este círculo de diálogo rebasa también lo personal en un sentido de contribuir a sociedades menos violentas, sin perjuicio de la necesaria autocrítica y de la necesidad, para algunos de ellos, de pedir perdón.

Dada la politización del tema y su sensibilidad en todos los países, los encuentros restaurativos se realizan, por lo general, con suma privacidad hasta que, en algunos casos, de una forma u otra, se conoce por los medios de comunicación. Una vez conocidos públicamente los encuentros, se incide en su debate público para ofrecer alternativas de respuesta y se cuestionan las asunciones sociales y del propio sistema penal respecto de la justicia restaurativa.

Se advierten diferencias entre los países respecto de los agentes que promueven o proponen el uso de los programas restaurativos ${ }^{24}$ (normalmente promovidos desde iniciativas individuales o grupales de víctimas o condenados); el momento en que se inician y su duración; el contexto en que se producen (incluyendo sus repercusiones jurídicas); las modalidades elegidas; y el número de personas implicadas. En cuanto a las cuestiones comunes, se subraya el respeto de los estándares mínimos internacionales referidos a la voluntariedad, la inclusión y participación, el empoderamiento, la seguridad, la confidencialidad, la honestidad, el respeto, la reparación, la responsabilización y la transformación (Department of Justice Canada, 2018; Quimby, 2021). Las ideas escuchadas pueden ponerse en relación con el manual de las Naciones Unidas sobre programas restaurativos que define el proceso de responsabilización (accountability) como la ayuda a aquellos que han causado un daño para reconocer y responsabilizarse por el daño y la reparación, y concreta el proceso de transformación en la acción de proporcionar oportunidades para el entendimiento, el remedio (healing) ${ }^{25}$, el cambio y la contribución a la restauración y la reintegración de las víctimas y los ofensores (United Nations, 2020, p. 6).

${ }^{23}$ Debe respetarse su voluntariedad de anonimato por lo que no se pueden ofrecer más detalles identificativos o que permitan trazar su identidad.

${ }^{24}$ Se utiliza el presente porque estos encuentros se siguen realizando.

25 Aquí puede entenderse que, en inglés, el término healing no se identifica únicamente con la idea de sanación o curación en un sentido estrictamente terapéutico. Además, su comprensión dentro de la justicia aborigen o comunitaria tiene que ver más con un sentido integrador u holístico, no terapéutico. 
Respecto de los elementos positivos comunes que destacan las víctimas de su participación en los programas restaurativos, en sus diferentes países, se encuentran el facilitar que las víctimas tengan un reconocimiento y voz, una oportunidad de ser oídas y una oportunidad, en su caso, de escuchar al ofensor. Asimismo, se menciona la posibilidad de plantear preguntas en relación con el derecho a la verdad y a la memoria; el tener una oportunidad de reparación (fundamentalmente simbólica, unida a la prevención); el sentir que de tanto sufrimiento puede crearse algo nuevo que rompa con la lógica de la violencia y la polarización actual; e incrementar el compromiso social por estos temas. Para las personas responsables del daño, esos elementos positivos también se aprecian en cuanto que se sienten interpelados por ellos, junto con el poder mostrar su cambio como personas.

Por otra parte, también se pone de relieve las diferencias entre víctimas, no tanto por países, sino por la existencia de víctimas menos escuchadas y a las que no se les da la posibilidad de acceso a la justicia restaurativa. Asimismo, entre en una minoría de personas condenadas se encuentran matices sobre la reflexión en torno a la justificación de la violencia, sin perjuicio de su rechazo actual. En este sentido se debatieron los conceptos de parresia y de agonismo (Marcello y Bueno, 2014).

\subsection{Rectificación, reconocimiento y reconexión como puentes entre las víctimas, las personas que cometieron el daño $y$ los jóvenes que las escuchan}

Surge así la idea de rectificación frente al daño cometido, aunque sea irreparable si ha supuesto la muerte de una persona, mostrando que las personas ya no son lo que fueron, que pueden cambiar. Son necesarios el reconocimiento como personas (de las víctimas por parte de los victimarios y de los victimarios por parte de las víctimas, así como de ambos por la sociedad), la reparación y la reconexión con la sociedad de las personas que se hacen responsables de la injusticia ocasionada a las víctimas, comprometiéndose ambos en el interés de que no vuelva a suceder en futuras generaciones. Estas consideraciones son de particular interés para los participantes más jóvenes que representan a la comunidad en el círculo de diálogo y que obligan a reflexionar sobre las condiciones culturales que favorecen la fascinación por la violencia, su naturalización o la indiferencia ante ella.

En relación con lo anterior, como hemos señalado en otros trabajos (Varona, 2021), desde la Victimología, Pemberton, Mulder y Aarten (2019) se detienen en el carácter ético de las experiencias de victimización, enlazado con su carácter narrativo, en relación con la necesidad de responsabilización y de reconocimiento de la injusticia y su impacto en vidas concretas, incluyendo la propia percepción de la víctima. 
Dicho carácter narrativo, preeminente actualmente en diversas áreas de las ciencias sociales y en particularmente en los estudios científicos y artísticos sobre la memoria (Bacci, 2015), debería debatirse más en profundidad y evitarse la utilización del término identidad en cuanto su construcción se realice por contraposición radical a otros o en tanto ofrezca la impresión de que puede bastar un relato único, más allá de la convicción ética de la injusticia del asesinato (Adichie, 2018). Aunque elaborar relatos puede parecer una acción previa, quizá deba ponerse el énfasis en la posibilidad de una conversación de narrativas, o mejor de experiencias, para poder entenderlas en su contexto, aunque no se comparta enteramente su significado (Fricker, 2007). En todo caso, para poder escuchar debemos confiar mínimamente en quien habla, quizá en ese orden expresivo al que ser refería Goffman (1970), con la posibilidad de compartir el sentido, tal vez interpretable con ese significado ético del que nos habla Reyes Mate y que podemos poner en relación con la cita indicada anteriormente de Zweig (2011).

\subsection{Rituales y energía emocional en los encuentros restaurativos}

En el círculo de diálogo se pone de relieve la importancia de los rituales conversacionales (Varona, 2020), donde víctimas y responsables de daños, así como facilitadores y personas jóvenes de la comunidad, de diferentes procedencias geográficas, se interpelan los unos a los otros. De este modo, en ese mismo círculo de diálogo o encuentro sobre encuentros restaurativos, se puede percibir la energía emocional a la que se refiere Rossner (2013; 2019). Esa energía emocional presente en la justicia restaurativa no puede limitarse únicamente a la solidaridad de las comunidades de cuidado y apoyo, para reparar y ser reparado, sino también al valor mismo del proceso de conversar (aquí estriba el valor procedimental de la justicia restaurativa, más allá de su resultado concreto en forma de acuerdo). Esta idea puede conectarse con la reinterpretación de Randell Collins (2005), dentro de la microsociología radical, que plantea dicho autor desde la lectura de la obra Interaction Rituals de Erving Goffman (1970), de la que parte también Rossner. El orden interactivo o expresivo se refiere a un conjunto o red de significados que tienen que ver con quiénes somos (aunque no en el sentido de una identidad monolítica), cuál es el propósito de la conversación y los motivos para estar en ella. Ese orden expresivo como compromiso ético recíproco supone una bella y útil ficción y se construye principalmente en la interacción conversacional, incluso en conversaciones difíciles en torno al terrorismo. Diversos expertos en comunicación señalan que el orden expresivo es frágil, pero es lo que da la confianza o seguridad para seguir conversando. Se trata de compartir el compromiso por querer recuperar la conversación. Cuando se rompe el orden expresivo, se 
siente humillación, vergüenza, enfado, confusión..., pero la confianza en poder restablecer el diálogo puede ser más fuerte. Esta idea resulta vital para entender qué es la justicia restaurativa como conversación reparadora inacabada.

En el mantenimiento de ese orden expresivo se cuestionan los límites impuestos a la victimidad en delitos graves. Víctimas y victimarios se salen del guión trazado por los profesionales del Derecho o los criminólogos. La victimización comienza con un suceso concreto, pero se desarrolla en el tiempo requiriendo procesos cognitivos de conexión o reconexión que demandan solidaridad y no implica exclusión de las personas que deben responsabilizarse al ser conscientes de dicha solidaridad. Esa solidaridad facilita la recuperación y también la capacidad de convivencia, incluso a largo plazo, con la esperanza de que los hijos o nietos "puedan cruzar puentes» que ellos no pueden ahora.

\subsection{El significado del perdón}

Como ya se ha comentado, para algunas personas que participaron (responsables de los daños o víctimas), el perdón es una necesidad, para otras no, pero, en todo caso, se circunscribe como algo muy personal, aunque pueda tener un valor social (Varona, 2017b). Además, cada persona expresa un entendimiento diferente del perdón en sus diferentes modalidades (unilateral, interpersonal, público; explícito, implícito, etcétera). Algunas víctimas aclararon que no podían ser cargadas ahora con la responsabilidad del perdón y la reconciliación ya que, en gran parte, particularmente este último proceso, es una tarea social, no individual o interpersonal. Algunas personas que se responsabilizaron de los daños encuentran la petición de perdón arriesgada por poder causar victimización secundaria, pero otras la necesitan sin esperar por ello nada a cambio.

\subsection{Impacto personal y eco social: memoria de lo irreparable para valorar y celebrar la vida única y en común}

Más allá del impacto personal, las personas participantes en el círculo están interesadas en la trascendencia social de los encuentros restaurativos realizados en sus países (y también del mismo círculo realizado en San Sebastián), potenciando en la sociedad el valor del cuidado por la vida, el diálogo, la no violencia y la no estigmatización propios de la justicia restaurativa (Braithwaite, 1989). Sobre las interacciones entre el impacto personal y el eco social, una de las víctimas participantes expresó lo siguiente (Varona, 2020, p. 71): 
Decir basta es abrir un pequeño resquicio en ese ámbar y permite ver más allá, con la ayuda de las personas facilitadoras. Estoy hablando de encuentros dolorosos pero saludables, que traen lo inesperado: ver la humanidad en el otro que asesinó y que ese otro pueda ver el daño que injustamente provocó. Puede apreciarse un cambio, lo que fueron los perpetradores y lo que son algunos ahora, después de los años. El dolor era mío pero pude ver que algunos perpetradores también sufrían al responsabilizarse por lo que habían hecho, unos perpetradores que creyeron actuar por una causa justa y crearon un mal irreparable, también en sus familias, en concreto, en sus hijos. El lamento es un lenguaje que se puede entender, compartir, pero hay que desarmarse para escuchar. Es muy difícil escuchar la verdad dolorosa. En mi caso, entre otras cuestiones, quería que supieran que fue una crueldad no enviar las cartas que escribió mi padre para despedirse de su familia antes de asesinarle. La pregunta de por qué, por qué a mí no tiene respuesta. También sufrí por el trato recibido por las instituciones. Pero ahora ya no siento que muero todos los días, aunque eche de menos a mi padre. Cuando veo sus fotos ya no las veo con un velo de temor. No tengo ni tendré un futuro con mi padre, pero sí un pasado que ahora, tras los encuentros restaurativos, me resulta más claro y menos doloroso.

Se percibe un interés en entender sin justificar, de saber sin odiar. Existe un vínculo traumático con el dolor que es elástico e, inseparablemente, personal y social. Se asume que todas las víctimas deben entenderse como «nuestras» víctimas, rompiendo los estereotipos ellos/ nosotros, sin justificaciones.

\subsection{Valor del arte colaborativo}

Durante el círculo de diálogo se trabajó con dinámicas de arte colaborativo, partiendo de una metáfora que puede remitir a los espacios en los que los victimarios y las víctimas se encuentran en sociedad, en cierta forma, suspendidos en el tiempo, por efecto de la violencia provocada y sufrida: ese espacio entre la marea alta y baja (Shoormal, en escocés, Gehzeiten, en alemán, ese tiempo para andar entre una y otra) (Aldington, 2020). Asimismo, se trabajó con la idea de «capas» de temor, que crean distancia y jerarquías, ocultan o invisibilizan, frente a su transformación compleja en «mantos» que protegen sin dejar de evidenciar la vulnerabilidad. Para ello, se realizó una actividad creativa, transformando telas que luego se conservaron por las personas participantes.

Asimismo, tras finalizar la sesión del primer día se realizó un recorrido conjunto desde el campus de Gipuzkoa al Peine de los Vientos, con una reflexión sobre el potencial simbolismo de las esculturas de Chillida en torno al presente, pasado y futuro, como claves de las dinámicas y preguntas alrededor de las cuales se trabaja habitualmente en justicia restaurativa. Se valoraron estas dinámicas como puertas abiertas a otra forma de descubrimiento y desarrollo comunitario de la paz. 


\section{Discusión e implicaciones prácticas}

Tras más de veinticinco años en continua expansión y evaluación comparada, la justicia restaurativa despierta hoy un gran interés ${ }^{26}$. Sin duda, conlleva grandes potencialidades, también en delitos de terrorismo. Sin embargo, es preciso mantener una actitud crítica porque no siempre lo que se dice restaurativo lo es o lo es mayormente.

Al hilo de la información disponible en su página web y de los magníficos textos recientemente publicados por la Secretaría General de Instituciones Penitenciarias (2020a; 2020b), así como de declaraciones recientes en los medios sobre la aplicación de la justicia restaurativa (Secretaría, 2020c) ${ }^{27}$, y las esperanzas puestas en un potencial modelo restaurativo con el traspaso de competencias a la Comunidad Autónoma del País Vasco (Gorospe, 2021), puede augurarse una extensión de dichos programas en nuestro país en el medio penitenciario. Esta extensión rompe las asunciones sobre el uso de la justicia restaurativa para delitos graves (delitos por los que puede llegarse a prisión, sin perjuicio de aplicarse también en medio abierto la justicia restaurativa). Resulta interesante el potencial mayor desarrollo de la justicia restaurativa en el medio penitenciario, quizá en parte porque se permite no estar tan constreñidos por los plazos procesales cuando los programas restaurativos se desarrollan en sede de instrucción y enjuiciamiento, sin perjuicio de las menciones a la justicia restaurativa en la anunciada reforma de la Ley de Enjuiciamiento Criminal.

26 Sobre el interés en el desarrollo de este tipo de programas, puede señalarse que, el 5 de enero de 2021, el cuerpo de funcionarios de prisiones de Eslovaquia remitió una pregunta sobre los programas restaurativos en prisión a todos los países integrantes de EUROPRIS.

27 Según la noticia recogida en su página web, en el Día Europeo de la Mediación, el Secretario General de Instituciones Penitenciarias expresó una apuesta inequívoca por la justicia restaurativa como complemento de la justicia penal tradicional: «Mientras esta gira en torno al delito y la noción del castigo, es una justicia retributiva, la Justicia Restaurativa es una justicia reparadora que pone su mirada en la transformación del delincuente y la escucha de la víctima, así como en la reparación del daño que se le causó». Los talleres de diálogos restaurativos comenzaron a impartirse en 2016 pero solo para aquellos penados a condenas alternativas a la prisión o los que se encontraban en la última fase de la ejecución de la condena privativa de libertad o tercer grado. De las 38 personas que participaron en 2017 en aquellos talleres, se han pasado a 855 participantes en 2020. Además, en 2019 se introdujeron programas restaurativos en el interior de las prisiones para delitos de carácter grave, con 61 participantes en 2020. Los talleres se incluyeron también como módulos de los programas de tratamiento de los delitos económicos (PIDECO), delitos de odio (programa «Diversidad») y delitos de violencia intrafamiliar (programa «Encuentro»). Para la realización de los encuentros restaurativos, Instituciones Penitenciarias contó con la colaboración de varios juzgados de Vigilancia Penitenciaria, la Fiscalía de Sevilla y algunos gobiernos autonómicos que - a través de las oficinas de Atención a las Víctimas - se pusieron en contacto con ellas (si bien se ha trabajado fundamentalmente con víctimas indirectas), así como con asociaciones de mediación, responsables de preparar a víctimas y condenados (Secretaría General de Instituciones Penitenciarias, 2021c). 
No obstante, precisamente por su similitud con cuestiones ya abordadas en los párrafos anteriores, conviene recordar los retos a los que se enfrentan los programas restaurativos en prisión. Estos retos ya han sido señalados, entre otros autores, por Brennan y Johnstone (2019), en su evaluación de diversos programas dentro del proyecto europeo de Building Bridges. Basado en el proyecto norteamericano denominado Sycamore tree project, con apoyo de la organización cristiana Prison Fellowship International y la Unión Europea, Brennan y Johnstone (2019) evaluaron dicho proyecto, desarrollado durante dos años en seis países, incluyendo España, con un estudio de caso específico en los Países Bajos, Portugal e Italia. El proyecto resultó particularmente interesante en delitos graves porque buscó favorecer una adecuada participación de las víctimas, sin excluir un enfoque socioecológico y de salud pública. Planteando cuestiones relevantes en cuanto a las diferentes culturas e infraestructuras penitenciarias, se centró en tres temas principales: cómo el papel marginal de las víctimas en la ejecución refuerza el punitivismo; el riesgo de caer en motivaciones pragmáticas para explorar alternativas en prisión en el contexto de crisis económica, con la limitación de medios para desarrollar verdaderos programas restaurativos; y la posibilidad de considerar diferentes necesidades y opciones de dinámicas restaurativas (más allá de la mediación, utilizando conferencias, círculos y otras prácticas).

En línea con los estándares internacionales, el libro de Brennan y Johnstone (2019) es interesante porque da cuenta de la relevancia de la evaluación externa de los programas restaurativos no sólo sobre el impacto en las personas participantes, fundamentalmente víctimas y ofensores, sino también en la sostenibilidad del programa en el sistema penal (cuestiones prácticas, factibilidad y aplicabilidad y aceptación por los trabajadores y gestores del sistema penitenciario). En este sentido, se detiene en cómo puede la justicia restaurativa ser transformadora en prisión, con el riesgo de buscar víctimas «adecuadas» y el riesgo de no colaborar con víctimas de todo tipo, por lo que podría mermarse el potencial participativo y comunitario que define los proyectos restaurativos, el cual probablemente requeriría de la entrada de voluntariado debidamente formado.

En relación con esos riesgos, terminamos esta contribución enumerando cinco aspectos que deben tenerse en cuenta para el desarrollo de la justicia restaurativa en la ejecución penal y penitenciaria, y que están presentes también en el debate planteado en el círculo de diálogo descrito anteriormente sobre la justicia restaurativa en casos de terrorismo en diversos países, si bien dentro de una contextualización diferente.

1. El desarrollo de la justicia restaurativa ha permitido romper mitos sobre las personas participantes (víctimas/ofensoras/personas de la comunidad cercana); sobre los fines teóricos y reales del sistema penal y penitenciario (Hassemer y Reemtsma, 2002); y sobre la justicia restaurativa como una justicia menor. 
2. Es preciso considerar cuáles son los objetivos de los programas restaurativos en prisión, analizar si están en línea con los estándares internacionales y con las posibilidades de transformación (Kim, 2020) y si se destinan los suficientes medios. Al hilo de ello y en relación con el traspaso de competencias en el País Vasco, en algunos foros, se ha mencionado la propuesta de la necesidad de espacios concretos en las prisiones (en particular en las de nueva construcción), con salas adecuadas e incluso recorridos creativos de justicia restaurativa. También se ha hecho hincapié en la formación de profesionales de régimen y tratamiento, no tanto para realizar dinámicas de justicia restaurativa, sino para que sean partícipes y se pueda fomentar un clima coherente - para evitar lo que Brennan y Johnstone (2019) denominan «sándwich punitivo»-, siempre con las limitaciones propias de la prisión y la necesidad de seguir extendiendo los valores de la justicia restaurativa en la sociedad para su mejor entendimiento y mayor uso (Braithwaite, 1989).

3. Deben considerarse los intereses prosociales de las víctimas (en los que coinciden muchas de las personas condenadas), más allá de planteamientos estrictamente terapéuticos o, por otra parte, centrados en el perdón, fomentando la no instrumentalización y la igualdad de acceso a los programas. Para ello es preciso, particularmente en delitos graves, partir de una formación victimológica, y evitar la idea de víctima ideal (Christie, 1986; 2009) para los programas de justicia restaurativa (Wemmers, 2002; Maglione, 2017; 2019; van Camp, 2017; Vanfraechem, Bolivar, y Aertsen, 2015). Ello implica también claridad informativa para las víctimas sobre los efectos penológicos (Alonso y Díaz Bada, 2016) (en mi opinión, debería evitarse la noción de derecho premial), efectos que son lógicos y razonables (y ajustados a los mencionados intereses prosociales), como ya existen en programas restaurativos en la fase de instrucción y enjuiciamiento, sin perjuicio de las dudas que sobre la sinceridad, suficiencia y dimensiones objetivas de la reparación puedan suscitarse en ocasiones.

En diversos estudios se pone de relieve cómo algunos programas caen en esa idea de la víctima ideal e, incluso, hablan de "historias o narrativas adecuadas" por parte de las víctimas (Brennan y Johnstone, 2019, p. 13, 28, 39, 92 y 103). Se alude, así, a una víctima recuperada, preparada, no demasiado vulnerable, que entienda el programa, etcétera, pero, en ocasiones, esa decisión se deja en manos de personas que, aunque excelentes profesionales, no tienen formación victimológica y que, además, pueden tener ciertos sesgos porque están más acostumbrados a trabajar con ofensores y, por ello también, contemplar la entrada de la comunidad - tercera pata de la justicia restaurativa- con recelo (Bolívar, 2019). 
Por ejemplo, frente a la preocupación de ser escrupulosos en seleccionar a la víctima, por contraste, en algunos programas se habla de que "casi cualquier ofensor» puede participar (Brennan y Johnstone, 2019, pp. 37 y 115). Según afirma Maglione (2017, p. 412), la víctima ideal puede ser utilizada como punto de referencia por los promotores o facilitadores de la justicia restaurativa, dirigiendo sus expectativas hacia los participantes que verán afectadas sus experiencias y éstas terminarán afectando también las políticas sobre programas restaurativos. Debe entenderse que las víctimas pueden ser manipuladas y equivocarse cuando demandan más pena, pero esa demanda no las transforma en victimarias. En todo caso, el acceso debería ser igualitario para víctimas y victimarios, particularmente porque está constatado que el impacto de la justicia restaurativa es mayormente positivo. Ese acceso no puede realizarse si se manejan asunciones falsas o perjuicios hacia las víctimas, los victimarios o la comunidad de apoyo. En particular, en los delitos graves, las víctimas no precedieron al victimario, fueron creadas por este. Las víctimas nunca merecieron lo que les ocurrió, por lo que determinadas personas, e incluso colectivos e instituciones, deben hacerse responsables ${ }^{28}$ porque, además, los victimarios, no surgieron de la nada, sino que son nuestros conciudadanos y, en ocasiones, vecinos y hasta familiares, y la sociedad debe fomentar una respuesta a la victimización que incluya la vuelta reflexiva de aquellos a la sociedad. Hacerse responsable en justicia restaurativa no significa estigmatizar ni excluir (Braithwaite, 1989; 2016; Daly, 2002; Dancig-Rosenberg, H. y Gal, 2012). La reconexión que requieren las víctimas es fundamentalmente de la sociedad para con ellas (Hassemer y Reemtsma, 2002), no se trata de un mero vínculo interpersonal entre víctima y victimario, como si de una mediación en el ámbito civil o familiar se tratara. Precisamente es el victimario el que tiene la responsabilidad, junto con las instituciones y la comunidad más cercana para reflexionar sobre las técnicas de neutralización o los mecanismos de desvinculación moral que favorecieron la victimización (Gustafson, 2018). La justicia restaurativa pone así en marcha mecanismos de vinculación para reparar y prevenir. Por ello, aunque deban hacerse más estudios, sin duda, la justicia restaurativa tiene un gran potencial e incrementa la empatía de las personas condenadas

28 Cuando hablamos de instituciones o colectivos que fomentaron o favorecieron la victimización secundaria nos referimos fundamentalmente a una responsabilidad ética, no penal. Aquí la ética no es moralismo de división del mundo en víctimas mitificadas o demonizadas, sino en el mínimo ético de rechazar la justificación del asesinato (Mate, 2011), por más que se deba recuperar al victimario para la sociedad. Sólo así las víctimas pueden valorar la sinceridad del lamento que conlleva un compromiso de no repetición. 
hacia la víctima y el resto de ciudadanos, y viceversa, así como la motivación para el cambio, lo que se relaciona con la reducción de la reincidencia o la renuncia o desistimiento de actividades delictivas, al tiempo que la sociedad se responsabiliza también de las condiciones que las hacen posibles (Kim, 2020).

4. Deben potenciarse modalidades de encuentros más allá de la mediación que permitan la participación de la comunidad más cercana (incluyendo el voluntariado formado, según se ha mencionado), como en el caso de las conferencias y círculos, que ya se desarrollan en muchos países de nuestro entorno, inclusive en proyectos restaurativos fuera de prisión, y se definen en los manuales de las Naciones Unidas como mayormente restaurativos.

5. Es preciso que los programas que se desarrollen sean evaluados externamente respecto del cumplimiento de sus objetivos, las modalidades y participantes, así como el impacto esperado e inesperado. La evaluación debe incluir los muchos intangibles presentes en la justicia restaurativa como proceso, valores y reparación simbólica. También debe analizarse, en términos de costeeficiencia, cuánto presupuesto se dedica a los programas, quiénes los desarrollan, con qué formación específica, particularmente para qué delitos, con qué impacto y cómo se rinden cuentas. Esa rendición de cuentas y su transparencia contribuirá a su legitimidad y mejora porque se fomentará el debate público y científico sobre la justicia restaurativa.

La justicia restaurativa, con todas sus limitaciones, si cumple con los estándares internacionales, debe entenderse como justicia que parte de lo que la experiencia de la injusticia hace a las personas afectadas y a la sociedad. No es una justicia menor o impunidad; tampoco es fundamentalmente terapia ni perdón, sino la posibilidad voluntaria de no crear más daños, mediante respuestas comprometedoras, preventivoreparadoras, más adecuadas a cada contexto y persona, también en el ámbito del terrorismo o de otros delitos graves. Ahora bien, para que los individuos puedan implicarse en la justicia restaurativa, la sociedad y las instituciones públicas (también las universidades ${ }^{29}$ ) deben comprometerse primero porque, de otro modo, la justicia restaurativa será el

${ }^{29}$ Recordemos que, además de la especialización posterior, el grado en Criminología es el único grado universitario en España que ofrece en su currículo asignaturas obligatorias de Victimología, Derecho y Sistema Penitenciario, Mediación y Justicia Restaurativa y Política criminal. En definitiva, en particular los grados públicos en Criminología, están formando con dinero público a personas que pueden tener la motivación y la formación para trabajar en el ámbito penitenciario en programas restaurativos, en concreto con un enfoque victimológico en delitos graves, tal y como se exige en los estándares internacionales. Sin embargo, no se reconoce esta formación en su potencial acceso laboral en este campo (Varona, 2018). 
privilegio de unos pocos, cuya selección dependerá de las asunciones de ciertos profesionales y la limitación de medios, y perderá todo carácter transformador.

\section{Bibliografía}

Adichie, C. N. (2018). El peligro de la historia única. Barcelona: Penguin.

Aertsen, I. y Pali, B. (dirs.) (2017). Critical Restorative Justice. Londres: Bloomsbury Publishing.

Aertsen, I., Arsovska, J., Rohne, H.-C., Valiñas, M. y Vanspauwen, K. (dirs.) (2018). Restoring Justice After Large Scale Violent Conflicts Kosovo, DR Congo and the Israeli Palestinian Case. Cullompton: Willan Publishing.

Albrecht, H.-J. y Kilchling, M. (2010). Victims of Terrorism Policies Should Victims of Terrorism be Treated Differently? En WADE, M. Y MalJEVIĆ, A. (dirs.). A War on Terror? The European Stance on a New Threat, Changing Laws and Human Rights Implications (pp. 221-241). Dordrecht: Springer.

Aldington, C. (2020). Cloaks of Encounters / Capes of the Shoormal; Reflections on two Creative Making Sessions as Part of a Workshop on Restorative Justice in Cases of Terrorism. En VARONA, G. (dir.) (2020). Caminando restaurativamente. Pasos para diseñar proyectos transformadores alrededor de la justicia penal (pp. 120-133). Madrid: Dykinson.

Alonso, R. y Díaz BADA, J. (2016). What Role Have Former ETA Terrorists Played in Counterterrorism and Counterradicalization Initiatives in Spain? Studies in Conflict \& Terrorism, 39 (11), 982-1006.

BAccI, C. (2015). Numeralia: Cuántas voces guarda un testimonio? Constelaciones. Revista de Teoría Crítica, 7, 528-536.

BaLdoli, R. (2020). Fighting Terrorism with Nonviolence: An Ideological Perspective. Critical studies on terrorism, 13(3), 464-484.

Bargen, C. ET AL. (2018). Serving Crime Victims through Restorative Justice. A Resource Guide for Leaders and Practitioners. Alberta Restorative Justice Association.

Bargen, C., Lyons, A. y Harman, M. (2019). Crime Victims' Experiences of Restorative Justice: A Listening Project. Ottawa: Department of Justice Canada.

Barr, T. S. (2013). Putting Victims in Prison. Restorative Justice, 1(3), 389-413.

Basit, T. (2003). Manual or Electronic? The Role of Coding in Qualitative Data Analysis. Educational research, 45(2), 143-154. https://doi.org/10. 1080/0013188032000133548. 
Bennett, C. (2007). Satisfying the Needs and Interests of Victims. En Johnstone. G. y Van Ness, D. W. (dirs.).Handbook of Restorative Justice (pp. 247-264). Cullompton: Willan.

Beristain, A. (2007). Víctimas del terrorismo. Nueva justicia, sanción y ética. Valencia: Tirant lo Blanch.

Bernuz, M. J. (2014). Las posibilidades de la justicia restaurativa en la justicia de menores (española). Revista Electrónica de Ciencia Penal y criminología, 16, 14.

Bertagna, G., Ceretti, A. y Mazzucato, C. (dirs.). (2015). Il libro dell'incontro. Vittime e responsabili della lotta armata a confronto. Milano: Il Saggiatore.

BianchI, H. (1994). Justice as Sanctuary: Toward a New System of Crime Control. Bloomington: Indiana University Press.

BIfFI, E. (2018). CJ Summer Courses, Barcelona - 3rd to 6th July 2018. Workshop Report. Lovaina: European Forum for Restorative Justice.

BIfFI, E. (2020). Policy Brief on Restorative Justice and Violent Extremism. Lovaina: European Forum for Restorative Justice.

BIFFI, E. y CHAPMAN, T. (2019). Restorative Justice. Ex post papers. RAN RVT and RAN Exit - Restorative Justice, 3-4 December 2019, Dublin, Ireland. Ran Center of Excellence.

BlagG, H. y Anthony, T. (2019). Restorative Justice or Indigenous Justice? En Blagg, H. y Anthony, T. Decolonising Criminology: Imagining Justice in a Postcolonial World (pp. 133-152). Londres: Palgrave Macmillan.

Bolivar, D. (2019). Restoring Harm: A Psychosocial Approach to Victims and Restorative Justice. Londres: Routledge.

Braithwaite, J. (1989). Crime, Shame and Reintegration. Nueva York: Cambridge University Press

BRAITHWAITE, J. (2016). Understanding terrorism through restorative justice. Disponible en www.johnbraithwaite.com. Fecha de la consulta 01/02/2021.

Brennan, I. y KlaAsen, E. (dirs.) (2015). Building Bridges. Restorative Dialogues between Victims and Offenders A Guide to Establishing and Running the Building Bridges Programme. JUST/2013/JPEN/AG Programme of the European Union. Disponible en http://restorativejustice.eu/bb/wp-content/uploads/sites/3/2016/02/WS-2-D2.4-BuildingBridges-Guidebook-.pdf. Fecha de la consulta 01/02/2021.

Brookes, D. (2002). Restorative Justice Training Manual. Edinburgo: SACRO.

CARLen, P. (2015). Contra la rehabilitación: en defensa de una justicia restaurativa. Crítica Penal y Poder, 9, 91-101. 
CARUTH, C. (1995). Trauma: Explorations in Memory. Londres: Johns Hopkins University Press.

Chapman, T. (2012). The Problem of Community in a Justice System in Transition: The Case of Community Restorative Justice in Northern Ireland. International Criminal Law Review, 12,1-15.

Chapman, T. (2018). «Nobody Has Ever Asked Me These Questions»: Engaging Restoratively with Politically Motivated Prisoners in Northern Ireland. En Lynch, O. Y Argomaniz, J. (dirs.) (2018). Victims and Perpetrators of Terrorism: Exploring Identities, Roles and Narratives. Londres: Routledge.

Chapman, T., Campbell, H., Wilson, D. y McCready, P. (2018). Working across Frontiers: Community Based Restorative Justice in Northern Ireland. En Vanfraechem, I. y Aertsen, I. (eds.) (2018). Action Research in Criminal Justice: Restorative Justice Approaches in Intercultural Settings. Londres: Routledge.

CHRISTIE, N. (1977). Conflicts as property. British Journal of Criminology, 17, 1-15.

Christie, N. (2009). Restorative Justice: Five Dangers Ahead. En KNEPPER, P., DOAK, J. y SHAPLAND, J. (dirs.) Urban Crime Prevention, Surveillance, and Restorative Justice. Effects of Social Technologies (pp. 195203). Boca Raton: CRC Press.

Collins, R. (2004). Interaction Ritual Chains. Princeton: Princeton University Press.

DALY, K. (2002). Restorative justice: The real story. Punishment \& Society, 4, 55-79.

Dancig-Rosenberg, H. y GaL, T. (2012). Restorative Criminal Justice. Cardozo Law Rev., 34, 2313.

Dandurand, Y. y Griffiths, C. T. (2006). Manual de principios justicia restaurativa. Nueva York: Naciones Unidas.

Davis, A. (2005). Abolition Democracy. Nueva York: Seven Stories.

DÜHRKHop, B. (2020). Reflections from the Basque Country. En G. VArona Martínez (dir.) (2020). Caminando restaurativamente. Pasos para diseñar proyectos transformadores alrededor de la justicia penal (pp. 113-119). Madrid: Dykinson.

EcheburÚA, E. (2007). Treatment Guidelines for Victims of Terrorism: A Comprehensive Approach. En The Integration and Management of Traumatized People after Terrorist Attacks (pp. 108-118). Amsterdam: IOS Press.

ERIKsson, A. (2009) Justice in Transition: Community Restorative Justice in Northern Ireland. Cullompton: Willan. 
FARALDO-CABANA, P. (2014). Luces y sombras del papel atribuido a los intereses patrimoniales de la víctima durante la ejecución de condenas por terrorismo. Oñati Socio-legal Series, 4 (3), 443-464.

FatTaH, E. A. (2019). Restorative Justice: Society's Steady March Towards a Civilized Justice Paradigm. Reino Unido: Amazon.

FeEst, J. (2015). Abolitionism. Some Answers to Frequently Asked Questions, Sortuz. Oñati Journal, 7 (2), 141-152.

Fourez, G. (2021). The Legal Recognition of Victims of Terrorism in Europe. En G. VARONA MARTínez (dir.), Macrovictimización, abuso de poder y victimología: impactos intergeneracionales (pp. 33-74). Cizur Menor: Aranzadi.

FrICKer, M. (2007). Epistemic Injustice: Power and the Ethics of Knowing. Oxford: Oxford University Press.

García-Vera, M. P. y SAnZ, J. (2016). Psychopathological Consequences of Terrorism: The Prevalence of Posttraumatic Stress Disorder in Victims of Terrorist Attacks. En Del Real Alcalá, J. A. (dir.). Fundamental rights and vulnerable groups. Sharjah, UAE: Bentham Science Publishers.

García ARRIZABalaga, I. (2019). Dimensión personal y dimensión social en los encuentros restaurativos: seis reflexiones en primera persona. En A. MARTín y M. P. Rodríguez (dirs.). Tras las huellas del terrorismo en Euskadi: Justicia restaurativa, convivencia y reconciliación. Madrid: Dykinson.

García Peñafiel, M., y Cartuyvels, Y. (2018). El método de análisis en grupo: un instrumento de formación en mediación, Oñati Socio-legal Series, 9(4), 477-493.

Gavrielides, T. (2018), Youth Radicalisation, Restorative Justice and the Good Lives Model: Comparative learnings from seven countries. Londres: The IARS International Institute.

Gil, A. y Maculan, E. (dirs.). (2017). La influencia de las víctimas en el tratamiento jurídico de la violencia colectiva. Madrid: Dykinson.

Goffman, E. (1970). El ritual de la interacción. Buenos Aires: Amorrortu.

Gustafson, D. L. (2018). Encountering The Other: Victim Offender Dialogue in Serious Crime. Tesis doctoral. KU Lovaina.

Hagemann, O. (2003). Restorative Justice in Prison? En L. Walgrave (dir.). Repositioning Restorative Justice (pp. 221-236). Portland: Willan.

Hagemann, O. (2012). Restorative Justice in the Context of Victim Needs and Coping Strategies of Victims. En Lummer, R., NAHrwold, M. y Süss, B. (dirs.). Restorative Justice - A victim Perspective and Issues of Co-operation (pp. 46-67). Kiel: SH Verband für Soziale Strafrechtspflege. 
Hassemer, W. y Reemtsma, J. P. (2002). Verbrechensopfer: Gesetz und Gerechtigkeit. Múnich: $\mathrm{CH}$ Beck.

Herrera, M. (2014). ¿Quién teme a la victimidad? El debate identitario en victimología. Revista de Derecho Penal y Criminología, 12, 343-404.

Hulsman, L. (1991). The Abolitionist Case: Alternative Crime Policies. Israeli Law Review, 25 (3-4), 681-709.

IgARTUA, I. (2015). Justicia penal restaurativa y justicia penal negociada, retórica y práctica. Estudio empírico del programa de mediación intrajudicial penal en Bizkaia. Tesis doctoral. UPV/EHU.

Johnstone, G. (2019). Restorative Justice and the Therapeutic Tradition. Looking into the Future. En T. GAVRIELIDES (dir.). Routledge International Handbook of Restorative Justice (pp. 395-408). Londres: Routledge.

Johnstone, G. y KlaAsen, E. (dirs.) (2015). Building Bridges: Restorative Dialogues between Victims and Offenders. Disponible en http://restorative-justice.eu/bb/wp-content/uploads/sites/3/2016/02/WS-2-D2.4Building-Bridges-Guidebook-.pdf. Fecha de la consulta 01/04/2021.

JoRge, A. P. (2021). What Works for Crime Victims: Criminal Justice, Victim Support Centers, and the Emotional Well-being of Crime Victims. Belo Horizonte: Editora Dialética.

KIM, M. E. (2020). Transformative Justice and Restorative Justice: Gender-based Violence and Alternative Visions of Justice in the United States. International Review of Victimology. DOI:10.1177/0269758020970414.

LAuwaert, K. (2015). European Criminal Justice Polices on Victims and Restorative Justice. En Vanfraechem, I., Bolivar, D. y Aertsen, I. (eds.) Victims and Restorative Justice (pp. 239-272). Londres: Routledge.

Letschert, R. M., Staiger, I. y Pemberton, A. (dirs.) (2010) Assisting Victims of Terrorism: Towards a European Standard of Justice. Dordrecht: Springer.

Maglione, G. (2017). Embodied Victims: An Archaeology of the «Ideal Victim» of Restorative Justice. Criminology \& Criminal Justice, 17(4), 401-417.

Maglione, G. (2019). The Political Rationality of Restorative Justice. Theoretical Criminology, 23(4), 545-562.

Marcello, F. de A. y Bueno Fischer, R. M. (2014). Cuidar de si, dizer a verdade: arte, pensamento e ética do sujeito. Pro-Posições, 25(2), 157-175.

Martínez Escamilla, M. y Sánchez Álvarez, M. P. (coords.) (2011). Justicia restaurativa, mediación penal y penitenciaria: un renovado impulso. Madrid: Reus. 
MARTínez Soto, T. (2016). Justicia restaurativa y terrorismo: perspectivas procesales para la reparación a las víctimas. Tesis doctoral. Universidad Carlos III de Madrid.

Mathiesen, T. (1974). The Politics of Abolition. Oxford: Martin Robertson.

McGarRY, R. y WalkLate, S. (2015). Victims: Trauma, Testimony and Justice. Londres: Routledge.

Muñoz, A. (2019). El Segundo Foro Jurídico, organizado por DV, debate sobre la justicia restaurativa, El Diario Vasco, 29.11.19, pp. 36-37.

Olalde, A.J. (2014). Restorative Encounters in Terrorist Victimization in Spain: Theoretical Reflections and Practical Insights from Social Work. Oñati Socio-legal Series, 4(3), 404-426.

Olalde, A. J. (2020). Caminares restaurativos en victimización grave. En VARonA, G. (dir.). Caminando restaurativamente. Pasos para diseñar proyectos transformadores alrededor de la justicia penal (pp. 135-162). Madrid: Dykinson.

Ollero, J. (2017). Pragmatic Abolitionism? Defining the Complex Relationship between Restorative Justice and Prisons. Restorative Justice, 5(2), 178-197.

PALI, B. (2018). Restorative Justice and Terrorism: Resisting Evil with Nonevil? Disponible en https://securitypraxis.eu/restorative-justice-andterrorism/. Fecha de la consulta 01/04/2021.

Pali, B. (2021). Moving Past the Worst Thing. Disponible en https://securitypraxis.eu/moving-past-the-worst-thing/?utm_ source $=$ Newsflash + EFRJ\&utm_campaign=93412e8739-EMAIL_ CAMPAIGN_2020_0\%E2\%80\%A6. Fecha de la consulta 01/04/2021.

Pali, B. Y PELIKAN, C. (2014). Con-texting Restorative Justice and Abolitionism: Exploring the Potential and Limits of Restorative Justice as an Alternative Discourse to Criminal Justice. Restorative Justice, 2(2), 142-164.

Pascual Rodriguez, E. (dir.) (2013). Los Ojos Del Otro: Encuentros restaurativos entre víctimas y ex miembros de ETA. Santander: Sal Terrae.

Pemberton, A. (2014). Terrorism, Forgiveness and Restorative Justice. Oñati Socio-legal Series, 4 (3), 369-389.

Pemberton, A., Mulder, E. y Aarten, P. G. (2019). Stories of Injustice: Towards a Narrative Victimology. European Journal of Criminology, 16(4), 391-412.

Pemberton, A., Winkel, F. W. y Groenhuijsen, M. (2007). Taking Victims Seriously in Restorative Justice. International Perspectives in Victimo$\log y, 3(1), 4-14$.

Pepinsky, H. (1998). Empathy Works, Obedience Doesn't. Criminal Justice Policy Review 9, 141-167. 
Pycroft, A. y Christensen-SchneIder, C. (2021). An Exploration of Trauma-informed Practices in Restorative Justice: A Phenomenological Study. International Journal of Restorative Justice.

Quimby, E. (dir.) (2021). Understanding and Applying Restorative Justice. Critical Readings on Why it's Needed and How it's Practiced. San Diego: Cognella.

ReIsyan, G. D. (2016). Neuro-Organizational Culture. Cham: Springer.

Reyes Mate, M. (2012). Tratado de la injusticia. Barcelona: Anthropos.

Ríos, J. C. AND ETXEBARRía, X. (2012). El valor de la palabra: encuentros restaurativos entre víctimas y condenados por delitos de terrorismo. Razón y Fe: Revista Hispanoamericana de Cultura, 265(1359), 71-80.

Rossner, M. (2013). Just Emotions: Rituals of Restorative Justice. Oxford: Oxford University Press.

Rossner, M. (2019). Restorative Justice, Anger, and the Transformative Energy of Forgiveness. The International Journal of Restorative Justice, 2(3), 368-388.

Ruiz Yamuza, F. G. y Ravagnani, L. (2018). Countering Islamic Radicalisation in Prison through Restorative Justice Based Programmes. ERA Forum, 18, 611-626.

Sherman, L. y StRAng, H. (2007). Restorative Justice: The Evidence. Londres: Smith Institute.

Soulou, K. (2017). Justice restaurative et terrorisme en Italie: de l'utopie á la réalité. Passe-Murailles, 67, 26-33.

Soulou, K. (2018). L'approche restaurative de la criminalité et son application aux cas de terrorisme. Les Cahiers de la Justice, 2, 343-359.

Steinert, H. (1988). Kriminalität als Konflikt. Kriminalsoziologische. Bibliographie, 58/59, 11-20.

SwaIn, J. (2018). A Hybrid Approach to Thematic Analysis in Qualitative Research: Using a Practical Example. Londres: Sage.

VAN CAMP, T. (2017). Understanding Victim Participation in Restorative Practices: Looking for Justice for Oneself as Well as for Others. European Journal of Criminology, 14(6), 679-696.

VAnfraechem, I. y Aertsen, I. (dirs.) (2017). Action Research in Criminal Justice: Restorative Justice Approaches in Intercultural Settings. Londres: Routledge.

Vanfraechem, I., Bolivar, D. y Aertsen, I. (dirs.) (2015). Victims and Restorative Justice. Londres: Routledge.

Varona, G., de la Cuesta, J. L. y Echeburúa, E. (2016). Victims of Terrorism in the Basque Country: Paradoxes of their Expectations and Demands in the end of ETA. Revista de Victimología, 3, 65-84. 
VARONA, G. y Soleto, H. (2014). Restorative Justice in Terrorist Victimisations: Comparative Implications: Introduction/Justicia Restaurativa en el Caso de Victimizaciones Terroristas: Implicaciones Comparativas: Introducción. Oñati Socio-legal Series, 4 (3), 345-350.

Varona, G. (1996). Restorative Justice: New Social Rites within the Penal System? Oñati: IISJ.

VARONA, G. (2012). Justicia restaurativa en supuestos de victimización terrorista: hacia un sistema de garantías mediante el estudio criminológico de casos comparados. Eguzkilore. Revista del Instituto Vasco de Criminología, 26: 201-245.

VARONA, G. (2013). The meaning of impunity: what do victims, offenders and society think of restorative encounters in the context of ETA terrorism in Spain? Restorative Justice, 1(2), 215-243.

VARONA, G. (2014). Who Sets the Limits in Restorative Justice and Why? Comparative Implications Learnt from Restorative Encounters with Terrorism Victims in the Basque Country. Oñati Socio-legal Series [online], 4(3), 550-572.

VARONA, G. (2017a). Restorative processes in the context of eta terrorist victimisations. En Quintero Olivares, G. ET aL, Terrorism in Spain: procedural approach (pp. 407-427). Valencia: Tirant lo Blanch.

Varona, G. (2017b). Apology and Spanish Criminal Law at the PostSentencing Level: the Gap Between Legal Provisions and Victims and Offenders' Experiences in Cases of Terrorism. Oñati Socio-Legal Series, 7(3).

VARONA, G. (2018a). La fundamentación victimológica de una reparación reforzada en casos de victimización terrorista (pp. 251-274). En VARONA, G. (ed.) Victimologia: en busca de un enfoque integrador para repensar la intervención con víctimas. Cizur Menor: Aranzadi.

VARONA, G. (2018b). Basque Country competing memories at the local, regional and state levels. Promoting public artistic events versus public institutional policies. En Hoondert, M., Mutsaers, P., Arfman, W., Cultural Practices of Victimhood. Taylor \& Francis Group.

Varona, G. (2018c). Justicia restaurativa desde la Criminología. Mapas para un viaje inicial. Madrid: Dykinson.

VARONA, G. (2019). Justicia restaurativa y justicia terapéutica: hacia una praxis reflexiva de transgresiones disciplinares. En E. PILlado (dir.). Justicia restaurativa y justicia terapéutica: hacia una praxis reflexiva de transgresiones disciplinares (pp. 25-55). Madrid: Dykinson.

VARona, G. (ed.) (2020a). Caminando restaurativamente. Pasos para diseñar proyectos transformadores alrededor de la justicia penal. Madrid: Dykinson. 
VARONA, G. (ed.) (2020b). Arte en prisión: justicia restaurativa a través de proyectos artísticos y narrativos. Valencia: Tirant lo Blanch.

VARONA, G. (2020c). Intersecciones de verdades sobre el pasado violento. En REED, M. y UMAÑA, C. (eds.). La búsqueda de la verdad: laberintos, ilusiones y expectativa (pp. 143-178). Bogotá: U. Externado de Colombia.

VARONA, G. (2021). Approaching victimology as social science for human rights. A Spanish perspective. Cizur Menor: Aranzadi.

VV. AA. (2008). Victims of Terrorism: Towards European Standards for Assistance. Executive Summary of the Literature Review. European Forum for Restorative Justice, International Victimology Institute Tilburg, Catholic University of Lovaina, Centre for the Study of Terrorism and Political Violence y Victim Support the Netherlands.

WALKLATE, S. (2016). Justicia restaurativa: ¿terapia y/o reconciliación? Revista de Victimología, (4), 83-104.

WeIteKAmp, E. G. y KeRner, H. J. (dirs.) (2012). Restorative justice: Theoretical foundations. Londres: Routledge.

Wemmers, J. A. (2002). Restorative Justice for Victims of Crime: A Victim-oriented Approach to Restorative Justice. International Review of Victimology, 9(1), 43-59.

White, S. (2020). Reflections from Northern Ireland. En G. VARONA MARTínez (dir.) (2020). Caminando restaurativamente. Pasos para diseñar proyectos transformadores alrededor de la justicia penal (pp. 111-112). Madrid: Dykinson.

Wood, W. R. y Suzuki, M. (2020). Are Conflicts Property? Re-examining the Ownership of Conflict in Restorative Justice. Social \& Legal Studies, 29(6), 903-924.

ZEHR, H. (2002). The Little Book of Restorative Justice. Intercourse, Pa.: Good Books.

ZweIG, S. (2012). Castellio contra Calvino: Conciencia contra violencia. Barcelona: Acantilado.

\section{Documentos}

Department of Justice Canada (2018). Principles and Guidelines for Restorative Justice Practice in Criminal Matters. Ottawa: Justice Canada.

EU CENTRE OF EXPERTISE FOR ViCTIMS OF TERRORISM (2020). Handbook on victims of terrorism. Bruselas: EUCVT.

European Forum FOR REstorative Justice (2018). Connecting people to restore just relations: Practice guide on Values and Standards for restorative justice practices. Lovaina: EFRJ. Disponible en www.euforumrj.org/ publications/research-reports. Fecha de la consulta 01/04/2021. 
European Forum For Restorative Justice (2020A). Leaflet document on the European Union Strategy on Victims' Rights (2020-2024). Disponible en https://www.euforumrj.org/sites/default/files/2020-04/EFRJ\%20 feedback $\% 20 \% 20$ to $\% 20$ EC $\% 20$ VR $\% 27 \% 20$ strategy $\% 202020-2024$.pdf. Fecha de la consulta 01/04/2021. Fecha de la consulta 01/04/2021.

European Forum for Restorative Justice (2020B). Thematic Brief on Restorative Justice and Sexual Violence. Lovaina: EFRJ.

KU Leuven (2016). Resources from the Project «ALTERNATIVE» on Justice and Security in Intercultural Conflicts. Disponible en www. alternativeproject.eu/publications. Fecha de la consulta 01/04/2021.

Secretaría General de Instituciones Penitenciarias (2020A). Taller de diálogos restaurativos: Responsabilización y reparación del daño. Madrid: Ministerio del Interior, Disponible en http://www.interior. gob.es/documents/642317/1201664/Taller_de_Di\%C3\%A1logos_Restaurativos_DP-23_web_126200630.pdf/af4b6ea9-c552-4acb-a67a3172ac9902f7. Fecha de la consulta 01/04/2021.

Secretaría General de Instituciones Penitenciarias (2020B). Intervención en justicia restaurativa: Encuentros restaurativos penitenciarios. Madrid: Ministerio del Interior. Disponible en http://www.interior. gob.es/documents/642317/1201664/Intervenci\%C3\%B3n_en_justicia_restaurativa_DP-24_web_126200539.pdf/323bebe7-cbfa-45d89cef-840ce824d693. Fecha de la consulta 01/04/2021.

Secretaría General de Instituciones Penitenciarias (2020c). Cerca de un millar de condenados participaron en 2020 en talleres de Justicia Restaurativa, 21 de marzo de 2021. Disponible en http://www.interior.gob.es/prensa/noticias/-/asset_publisher/GHU8Ap6ztgsg/content/ id/12815797. Fecha de la consulta 01/04/2021.

Sistiaga, J. y CoRtés-Cavanillas, A. (dirs.) (2019). Zubiak (documental) (90mi). Movistar+, La Caña Brothers.

United Nations (2020). Handbook on Restorative Justice Programmes. Viena: United Nations Office on Drugs and Crime (UNODC)

United Nations (2016). Handbook on the Management of Violent Extremist Prisoners and the Prevention of Radicalization to Violence in Prisons. Nueva York: United Nations.

\section{Prensa}

GoRosPE, P. (2021). Euskadi mira a Cataluña para su modelo de cárceles. El Gobierno vasco quiere acelerar la rehabilitación, la justicia restaurativa y el régimen abierto de los internos, El País, 7 de marzo de 2021. Disponible en https://elpais.com/espana/2021-03-06/euskadi-mira-a-catalunapara-su-modelo-de-carceles.html. Fecha de la consulta 01/04/2021. 